\title{
REVALORIZAÇÃO DO MODELO DE MILES: LIÇÕES DAS TEORIAS DE REDES PARA DECISÕES ESTRATÉGICAS
}

\author{
Ernesto Michelangelo Giglio \\ ernesto.giglio@gmail.com \\ Universidade Paulista - São Paulo, SP/Brasil \\ Luciana Massaro Onusic \\ lucianaonusic@gmail.com \\ Universidade Federal de São Paulo - São Paulo, SP/Brasil
}

\begin{abstract}
Recebido em 10/11/2011
Aprovado em 04/01/2013

Disponibilizado em 01/04/2013

Avaliado pelo sistema double blind review

Revista Eletrônica de Administração

Editor: Luís Felipe Nascimento

ISSN 1413-2311 (versão on-line)

Editada pela Escola de Administração da Universidade Federal do Rio Grande do Sul.

Periodicidade: Quadrimestral

Sistema requerido: Adobe Acrobat Reader.
\end{abstract}

\section{RESUMO}

O objetivo do trabalho é revalorizar o modelo de estratégias de Miles e colaboradores, que foi apresentado na década de 1970, e colocá-lo num quadro teórico de redes de negócios, já que tanto os autores originais, quanto os trabalhos posteriores colocam as incertezas do meio e as relações entre empresas, que são princípios valorizados nas teorias de redes, como o fundamento para as decisões estratégicas. A proposição orientadora é que a opção dos pequenos empresários por uma das quatro estratégias do modelo pode ser explicada a partir de suas conexões na rede em que estão imersos. O argumento é sustentado pela análise das convergências de artigos internacionais sobre as bases e capacidades do modelo e pela análise de pesquisas brasileiras com pequenas empresas, nas quais o modelo foi aplicado, buscando suas relações com variáveis demográficas, econômicas e de recursos das empresas. A interpretação é que esses trabalhos utilizaram os princípios de redes, embora não o tivessem explicitado. $\mathrm{O}$ artigo oferece um benefício teórico, com o suporte da teoria de redes para o modelo de Miles; oferece um benefício metodológico ao indicar que as variáveis de rede, tais como centralidade, densidade, conteúdo de fluxo e comprometimento, seriam as antecedentes principais para a determinação da posição estratégica da empresa e cria um benefício gerencial, ao apresentar um modelo que é aplicável a pequenas empresas, com capacidade de distinção entre as quatro estratégicas, ou seja, é possível determinar a estratégia que a empresa está seguindo, mesmo que não explicitada pelos seus dirigentes e indicar as possibilidades de movimentos para novas posições.

Palavras-chave: Estratégia; Teoria de Redes; Modelo de Estratégia de Miles. 


\title{
REVALUATING THE MILES MODEL: THE NETWORKS THEORIES LESSONS FOR STRATEGIC DECISONS
}

\begin{abstract}
The objective of this work is to revaluate the Miles' strategy model, which was presented in 1970, and insert it in a theoretical frame of business networks, since both the original author and posterior works put the uncertainty of the environment and the relations between companies as the foundation for strategic decision, which are principles of the network theories. The lead proposition is that the option for one of four strategies from the model by small businesses can be explained by its connections in the network in which they are immersed. The argument is sustained by the analysis of the convergence of international articles about the basis and capacities of the model and by the analysis of brazilian researches with small businesses, in which the model was applied, searching for its relations with demographic, economic and companies' resources variables. Our interpretation is that these works have utilized the principles of networks, although not explicitly. The article creates a theoretical benefit with the support of the network theory for the model; it creates a methodological benefit by indicating that the network variables, such as centrality, density, flow content and commitment, would be the main antecedents to determining the strategic position of the company; and it creates a managerial benefit by presenting a model which is applicable to small businesses, with the capacity of distinguishing between the four strategies, in other words, it is possible to determine the strategy that the company is following, even when it is not made explicit by its managers and the possibilities of movement to new positions.
\end{abstract}

Keywords: Strategy; Network Theory; Miles' Strategy Model.

\section{INTRODUÇÃO}

Há quase quatro décadas, quando o pensamento em estratégia era essencialmente caracterizado pelas ideias de Porter (1980), Chandler (1977), Mintzberg (1987) e Ansoff (1979), foi publicado o Modelo de Miles e colaboradores ${ }^{1}$ (1978), doravante apenas denominado de Modelo de Miles, que se propunha a classificar estratégias competitivas adotadas pelas empresas. Naquela oportunidade, o conhecimento disponível acerca dos conceitos de redes ainda não se mostrava incorporado à literatura de gestão estratégica. Desde então se observa o crescimento do interesse de comunidades acadêmicas pelo estudo de redes empresariais, independentemente do porte das empresas. Diante desse contexto e a par da relevância da consideração da empresa como ator pertencente a redes e, não menos importante, das especificidades das empresas de menor porte; o objetivo deste artigo é revisar o Modelo de Miles, incorporando aspectos decorrentes do nível de inserção das empresas em redes. Para alcançar o objetivo do estudo são utilizados os conceitos de sociedade em rede

\footnotetext{
${ }^{1}$ Miles, Snow, Meyer e Coleman em 1978 apresentam uma tipologia de decisões estratégicas, intitulada "Organizational strategy, structure and process" e publicada na revista The Academy of Management Review.
} 
Revalorização do modelo de Miles: lições das teorias de redes para decisões estratégicas

segundo Castells (1999) e conceitos de redes sociais apresentados por Granovetter (1985) e Nohria e Ecles (1992), os quais foram aplicados a estudos já realizados em 413 pequenas empresas no Brasil, conforme apresentado no item 3.2.

O foco do modelo nas pequenas empresas foi uma de suas características desde sua publicação. Com a revalorização das pequenas empresas, que ocorreu a partir da década de 1980, em consonância com grandes mudanças políticas; econômicas, como a globalização da produção e do consumo; mudanças tecnológicas, com o microcomputador possibilitando conexões antes impossíveis; e mudanças sociais, com a emergência de uma sociedade em rede; abriu-se a possibilidade delas participarem de processos produtivos globais e a possibilidade de se associarem, tanto verticalmente, constituindo redes de produção verticais; quanto horizontalmente, constituindo redes de cooperação horizontais.

Essa reorganização dos arranjos de mercado, ou seja, a inserção e a importância emergente das pequenas empresas na produção compartilhada, despertou a atenção dos pesquisadores, que buscaram novas teorias e modelos sobre as estratégias das empresas nesse formato. É neste ponto que o modelo de Miles aparece como uma das respostas. A presente proposta é investigá-lo e discutir suas possibilidades explicativas e de aplicação, dando-lhe o suporte das teorias de redes.

O tema é relevante porque as pequenas empresas são mais vulneráveis às mudanças do ambiente de mercado e necessitam de estratégias distintas daquelas das grandes empresas, que tem um guarda chuva de produtos e podem resistir melhor às variações. Conforme dados do Sebrae (2011) a ausência de uma estratégia coerente com as capacidades da empresa e a mutabilidade do ambiente é um dos principais motivos do alto índice de mortalidade de pequenas e micro empresas.

A intenção é colocar o modelo de Miles na perspectiva de redes de negócios, principalmente considerando as afirmativas da sociedade em rede (CASTELLS, 1999) e as afirmativas das redes sociais (GRANOVETTER, 1985; NOHRIA e ECLES, 1992). Neste trabalho utiliza-se a afirmativa de Nohria e Ecles (1992) que todas as empresas estão em rede, quer utilizem, ou não, suas conexões. A densidade dessas conexões e a natureza das trocas entre os atores constituem a estrutura da rede. Quanto mais imbricada estruturalmente, socialmente e economicamente, maiores as chances de uma empresa fortalecer sua posição competitiva e/ou realizar movimentos estratégicos. Conforme Nohria e Ecles (1992) a vantagem competitiva de uma empresa não está em seus recursos materiais, ou humanos, mas sim na sua posição numa rede de empresas, a qual lhe possibilita acesso e uso de recursos coletivizados. 
Colocando o modelo de Miles na perspectiva dos princípios dos autores citados afirma-se que a escolha de uma das quatro estratégias nele descritas - a prospectora, a defensiva, a analítica e a reativa- pode ser compreendida a partir da posição e dos fluxos da empresa na rede.

A estrutura do artigo inicia com esta introdução, explicitando o objetivo, a justificativa e os benefícios do trabalho. Em seguida serão abordados os principais pontos do modelo de Miles. Na sequência serão apresentadas as discussões e aplicações do modelo num painel de artigos internacionais e nacionais, comentando os esforços dos autores em buscar variáveis antecedentes. Como resultado dessas análises mostra-se a proposta de inserção do modelo na teoria de redes, com algumas afirmativas sobre as consequências teóricas e metodológicas. Nas conclusões recupera-se o caminho percorrido e apresentam-se as consequências e desdobramentos da posição aqui defendida.

\section{O MODELO DE MILES, SNOW, MEYER E COLEMAN}

Na década de 1970 surgiram algumas correntes, modelos e ferramentas de estratégias, entre elas, a matriz BCG (apresentada no inicio dos anos 70), a ferramenta PIMS (Profit Impact of Market Strategy), o livro Strategic Management de Ansoff (primeira edição em 1979), o livro Estratégia Competitiva de Porter (primeira edição em 1980). Também nessa década apareceram análises de cenários, algumas das quais se tornaram mais conhecidas, tais como as apresentadas no livro O Choque do Futuro de Alvim Tofler e Megatrends, de John Naisbitt (apresentado em 1982). Algumas discussões praticamente sem fim (pois partiam de premissas insolúveis), como a valorização do ambiente externo determinando os rumos da empresa, contra a valorização do ambiente interno, ocupavam congressos e revistas. Nessa trilha surgiam modelos que ora valorizavam os recursos da empresa, como o RBV (cuja origem pode ser rastreada até 1950), ora valorizavam as influencias externas, como a teoria dos stakeholders e a teoria da ecologia organizacional. Era um período, portanto, de competição de teorias e modelos.

Nessa década de 1970 apareciam os primeiros sinais da grande mudança social e tecnológica dos modos de relacionamento entre as pessoas e de produção nas empresas, com o primeiro microcomputador sendo lançado no mercado em 1975. É nesse contexto de mercado e de discussões teóricas que Miles et al. (1978) apresentaram seu modelo na revista The Academy of Management Review, em 1978, reimpresso em 1986.

A afirmativa central do texto original é que as empresas precisam se adaptar às incertezas do ambiente e às suas interdependências e para isso precisam ser flexíveis e essa 
Revalorização do modelo de Miles: lições das teorias de redes para decisões estratégicas

condição não se obtém facilmente. Na sequência o artigo desenvolve afirmativas sobre o processo (as decisões) de adaptação estratégica e apresenta uma tipologia, uma espécie de ordem e classificação desses processos.

Para a tomada de decisão os estrategistas precisam considerar a capacidade empreendedora da empresa, no sentido de inovação e adaptação; a capacidade de engenharia, no sentido de aplicabilidade e tecnologia disponível para implantar as decisões; e a capacidade administrativa, no sentido de poder contar com recursos materiais e humanos. Analisando esses pontos, os empresários podem decidir por uma estratégia.

Segundo os autores, o conteúdo das estratégias pode ser agrupado em quatro grandes categorias, sendo três consideradas realmente como estratégias e uma categoria considerada como uma resposta inadequada; cada uma das quais resultando nas decisões e processos dos problemas de empreendedorismo, engenharia e administrativo, conforme condições do ambiente. É, portanto, uma classificação que valoriza o meio ambiente, mas também coloca que o resultado final depende de uma conjugação de fatores e decisões dos empresários. Conforme os próprios autores, sua tipologia engloba as relações e decisões internas da empresa com as relações dinâmicas com o ambiente. Conforme abordagem deste trabalho, são essas relações com o meio ambiente que foram subestimadas na época e que agora podem ser revalorizadas.

A seguir foram resumidas as características das quatro categorias.

\subsection{A estratégia defensiva}

Esta estratégia é adotada por empresas que se encontram em mercados que são dominados pelos concorrentes. Consiste em desenvolver atividades e características distintas, longe dos campos de domínio dos concorrentes. Obtida uma posição no mercado, ela é defendida no sentido de ser mantida. Sua palavra chave seria controle. Ao adotar esta estratégia, uma empresa limita sua área de atuação, reduz a necessidade de investimento em tecnologia e ajustes na estrutura operacional, focando apenas na eficiência das operações e processos já existentes. A empresa dificilmente é atacada pelos concorrentes, ou pressionada pelos fornecedores, pois praticam preços competitivos e excelência nos serviços sob seu domínio. Por outro lado, fica muito dependente da fidelidade e imutabilidade do seu mercado (MILES et. al, 1978:48).

Esta estratégia, portanto, necessita de um mercado específico e estável, para o qual suas habilidades e recursos são valorizados. Para os autores do modelo, o negócio de processamento de alimentos seria um exemplo. Os autores utilizaram a metáfora da máquina 
para distinguir esta estratégia com os seus controles e estabilidade, raciocínio que foi detalhado por Morgan (1996) alguns anos depois.

Conforme será defendido no item de interface entre as estratégias e as teorias de redes, esta posição estratégica depende de uma rede de relações relativamente fechada e estável.

\subsection{Estratégia prospectora}

As empresas que decidem pela estratégia prospectora buscam, continuamente, novas oportunidades no mercado de forma pró-ativa, investindo em pesquisa e desenvolvimento, realizando mudanças em sua área de atuação, bem como criando novos negócios. Sua palavra chave seria flexibilidade. Seria praticamente o oposto da estratégia defensiva, já que aqui a empresa renova seus mercados consumidores, abandona produtos em ciclo de vida de maturidade e declínio; torna-se visível aos concorrentes e pode até incomodá-los, conforme seus movimentos no mercado.

A busca constante de inovação pode ocasionar baixos retornos, mas, por outro lado, a empresa aprende e desenvolve flexibilidade na produção e conhece os movimentos dos consumidores. Ao contrário da estratégia defensiva, aqui a gestão é flexível, sensível às mudanças e as atividades são descentralizadas. Utilizando o raciocínio da ecologia ambiental (BAUM, 1998, apud CLEGG, HARDY e NORD, 1998), a empresa prospectora tende a ser mais eficaz em mercados dinâmicos e inovadores, tais como a industria dos videogames. Os autores usam a metáfora do organismo, com constante adaptação ao meio.

No item de interface entre as estratégias e as teorias de redes, esta posição estratégica depende de uma rede de relações aberta, com laços fracos, onde a inovação é valorizada e a informação flui entre os atores. As redes da Internet onde fabricantes e consumidores trocam idéias seria um exemplo desse formato.

\subsection{Estratégia analítica}

A empresa que adota a estratégia analítica estaria a meio caminho entre a estratégia defensiva, que estabelece um círculo fechado, e a estratégia prospectora, que é aberta. Sua palavra chave seria balanço. A empresa estaria imersa em dois tipos de mercado sendo um mais estável e outro mais dinâmico. Para tal é necessário desenvolver um leque de produtos e serviços que atenda aos dois mercados, o que pode exigir uma divisão interna. Conforme interpretação de Slater e Narver (1993), as empresas que adotam este tipo de estratégia são também chamadas de imitadores criativos, por absorverem e melhorarem inovações dos concorrentes. Nesse sentido elas se diferenciam das prospectoras, porque diminuem seus 
Revalorização do modelo de Miles: lições das teorias de redes para decisões estratégicas

riscos de desenvolvimento e lançamento de produtos. Esta imitação exige muito esforço e custo em pesquisas de adaptação de produtos, já que os processos já citados (capacidade empreendedora, de engenharia e administrativa) não são os mesmos da empresa que originou o produto. Outro problema está no balanço dos recursos para atuar em mercados estáveis e dinâmicos, já que não se trata de uma simples conta aritmética.

Afirmam Miles et al. (1978) que esta estratégia é utilizada por pequenas empresas que se encontram em crise. Como estratégia de sobrevivência, o pequeno empresário analisa o mercado e replica produtos de sucesso, ao mesmo tempo em que continua com seus produtos tradicionais. Os autores afirmam que é necessário haver uma coalizão interna para que o balanço funcione. A estrutura matricial é dada como a mais competente, permitindo certo controle e flexibilidade.

No item de interface entre as estratégias e as teorias de redes, esta posição estratégica depende de uma rede aberta, com laços fracos, porém, com certo grau de centralização e regras definidas sobre os comportamentos dos empresários.

\subsection{A resposta reativa}

A empresa que adota a resposta reativa percebe as mudanças no ambiente, mas não consegue responder na forma e velocidade necessárias, ou por falta de flexibilidade, ou por falta de recursos. As mudanças são feitas apenas devido a pressões do ambiente externo. Sua dominância na empresa pode ocorrer por três motivos: A. Dificuldade da administração em articular uma estratégia viável; B. A estratégia existe, mas a tecnologia, a estrutura e os processos não estão vinculados a ela de maneira adequada; C. A administração segue um caminho especifico de relação entre a sua estrutura e a sua estratégia, mesmo que tal definição não esteja mais adequada às condições de mercado (isto é, pode ter sido apropriada no passado, mas no presente não o é).

No item de interface entre as estratégias e as redes de negócios, afirma-se que esta situação ocorre quando uma empresa ocupa uma posição periférica numa rede de empresas, o que restringe o seu acesso a recursos e informações. Uma empresa de assistência técnica de eletrônicos, que não mantém vínculos estreitos com os fabricantes e com a rede de peças seria um exemplo. A segunda possibilidade é que a empresa participa de uma rede muito fechada de empresas, que não se adapta às mudanças do ambiente. Um grupo familiar fechado que segue as tradições de produção artesanal de produtos agrícolas poderia ser um exemplo. 
Ernesto Michelangelo Giglio \& Luciana Massaro Onusic

Recuperadas as principais afirmativas das quatro estratégias, com algumas hipóteses já delineadas, analisam-se no próximo item as discussões e aplicações do modelo na produção científica da Administração.

\section{METODOLOGIA}

Considerando que o artigo caracteriza-se em parte como um ensaio formal, conforme Severino (2000), com análise de lacunas nas teorias e instrumentos e defesa de uma proposta; e em parte como artigo científico, que pesquisa argumentos e fatos para sustentar uma proposição; foram analisados artigos já existentes na literatura nacional e internacional que discutiram e aplicaram o modelo de Miles.

Relativo à amostra de artigos internacionais, o foco da análise foi investigar os esforços de operacionalização do modelo e os sinais de presença, ou ausência das variáveis de rede. Sobre a amostra de artigos brasileiros, o foco da análise foi buscar os pontos nos quais a inserção das variáveis de redes poderia acrescentar qualidade às conclusões. ${ }^{2}$

Seguindo as normas técnicas de pesquisas bibliográficas críticas (BURREL e MORGAN, 1979; DEMO, 1995; LATOUR, 2005; MARSDEN, 1990; VIZEU, 2003; YIN, 2005) buscaram-se artigos nas bases de dados internacionais Ebsco e Proquest, que constituem dois dos melhores bancos de dados sobre a produção mundial, colocando-os numa ordem cronológica. A coleta se encerrou quando os dados indicaram as convergências. Quadro 1.

Para realizar a pesquisa, o trabalho foi construído conforme as fases apresentadas no

Quadro 1 - As fases do desenvolvimento da pesquisa sobre os conceitos de redes aplicados ao modelo de Miles

\begin{tabular}{|l|l|}
\hline \multicolumn{1}{|c|}{ Fases } & \multicolumn{1}{c|}{$\begin{array}{c}\text { Tipo de Procedimento e } \\
\text { Ferramenta Empregada }\end{array}$} \\
\hline 1. Levantamento e resumo do modelo proposto por Miles et al. (1978) & $\begin{array}{l}\text { Levantamento manual em bases } \\
\text { Ebsco e Proquest }\end{array}$ \\
\hline $\begin{array}{l}\text { 2. Levantamento, resumo e análise de artigos internacionais e brasileiros } \\
\text { que aplicaram e discutiram o modelo de Miles. }\end{array}$ & $\begin{array}{l}\text { Levantamento manual em bases } \\
\text { Ebsco e Proquest e outros endereços } \\
\text { da internet. }\end{array}$ \\
\hline $\begin{array}{l}\text { 3. Levantamento e análise da explicação de processos e escolhas } \\
\text { estratégicas a partir dos conceitos de redes. }\end{array}$ & $\begin{array}{l}\text { Levantamento manual em bases } \\
\text { Ebsco e Proquest }\end{array}$ \\
\hline $\begin{array}{l}\text { 4. Proposta da utilização dos conceitos de redes como suporte para o } \\
\text { modelo de estratégias de Miles. }\end{array}$ & $\begin{array}{l}\text { Conclusões unindo as análises de } \\
\text { conceitos e os casos apresentados. }\end{array}$ \\
\hline
\end{tabular}
Fonte: Autores

\subsection{Comentários sobre os artigos internacionais}

$\mathrm{Na}$ literatura internacional o modelo de Miles foi testado e discutido desde a sua apresentação. Nas duas décadas seguintes à publicação a tendência dos artigos era testar e

\footnotetext{
${ }^{2}$ Os autores realizam atualmente um trabalho de teste de um instrumento com a adição das variáveis de rede, mas entende-se que ainda não é o momento de apresentar os resultados dessa pesquisa.
}

REAd I Porto Alegre - Edição 74 - № 1 - jan/abr 2013 - p. 192-218 
Revalorização do modelo de Miles: lições das teorias de redes para decisões estratégicas

melhorar o modelo. Como exemplos podem-se citar Hambrick (1983), que testou a efetividade do modelo em pequenas empresas, afirmando que a força do ambiente havia sido subestimada no original; Shortell e Zajac (1990) que trouxeram evidencias de validade do modelo; Dvir, Segev e Shenhar (1993) que valorizaram a variável tecnologia como importante na definição das estratégias; Conant e colaboradores (1990) que construíram um instrumento com frases com quatro alternativas, cada uma delas referente a uma das estratégias.

$\mathrm{Na}$ década de 2000 houve maior incidência de análises ambientais relacionadas ao modelo, acompanhando as mudanças sociais e tecnológicas no mundo. Como exemplos podem-se citar Desarbo et al. (2004) que criaram uma variante do modelo, estatisticamente aplicável, com a inclusão de variáveis de incertezas ambientais, tais como mudanças dos consumidores. Essa inserção do ambiente mostra uma mudança de paradigma dos recursos internos para a dependência do ambiente.

Encontrar textos que contenham relação entre o modelo e as teorias de redes é mais raro. Começando pelos próprios autores, Miles e Snow (1986:62) afirmaram que há uma revolução em andamento e que as redes dinâmicas são a nova forma de organização. Para entender as decisões e estratégias de uma empresa não basta investigá-la isoladamente, é necessário ver a rede toda. Mais tarde Miles e Snow (1992) discutiram como as redes podem falhar se os gerentes não souberem agir nesse novo formato. Nesse artigo os autores já estavam convictos que a rede era a nova estrutura das organizações, substituindo os formatos funcionais e matriciais e que os insucessos se deviam a erros funcionais (numa cadeia, por exemplo) e erros de decisão (sobre leque de produtos, por exemplo). Miles et al. (1997) discutiram o que chamavam de estrutura esférica da organização, já utilizando um raciocínio de estrutura de redes.

Como se percebe, os próprios autores do modelo consideram a necessidade de se entender as escolhas estratégicas e a gerência das organizações pelos conceitos de redes. No entanto, essa posição pouco evoluiu, pois não havia uma teoria claramente estabelecida sobre as redes de negócios. A proposta deste manuscrito é que os conceitos mais atuais de fluxo e posição na rede podem dar o fundamento teórico que o modelo carece. A teoria também pode ser capaz de explicar os comportamentos dos empresários, nas suas escolhas sobre os destinos da empresa.

A seguir apresenta-se a pesquisa sobre os artigos brasileiros. 
Ernesto Michelangelo Giglio \& Luciana Massaro Onusic

\subsection{Comentários sobre os artigos brasileiros}

Na literatura brasileira sobre o modelo de Miles existem mais textos empíricos do que reflexivos e são raros os artigos que buscam uma interface entre o modelo e a teoria de redes. Sobre textos reflexivos pode-se citar Barbosa e Teixeira (2003) onde se afirma que os empresários não sabem considerar as influencias do ambiente; Hoffman e colaboradores (2009) que afirmam que o recurso tecnológico é a variável mais importante na tomada de decisão, o que nem sempre é considerado pelos estrategistas; Moori, Ghobril e Marcondes (2009) que reafirmaram a dependência da decisão estratégica conforme o ambiente da empresa e Hoffman, Molina-Morales e Martinez-Fernandez (2007), que apresentaram uma classificação de redes de negócios que se apóia em alguns pressupostos de estrutura do modelo de Miles.

Os textos empíricos que tem mais fundamentação teórica e metodológica estão resumidos a seguir.

A. Hofer et al. (2010) pesquisaram 34 pequenas empresas situadas na cidade de Curitiba, buscando analisar suas estratégias, o perfil de seus gerentes e suas decisões quanto às estratégias adotadas. Os respondentes eram oriundos de vários negócios e as questões versavam sobre o perfil da empresa, o contexto da empresa e a estratégia utilizada. A pesquisa, portanto, inseriu o meio ambiente. Os resultados podem ser vistos na Tabela 1.

Tabela 1 - A escolha de estratégias de pequenos empresários de Curitiba, conforme o modelo de Miles

\begin{tabular}{lcc}
\hline \multicolumn{1}{c}{ Estratégia } & Frequência & \% \\
\hline Prospectora & 14 & 41 \\
Analítica & 14 & 41 \\
Defensiva & 4 & 12 \\
Reativa & 2 & 6 \\
Total & 34 & 100 \\
\hline Fonte: Adaptado de Hofer et al. $(2010: 156)$
\end{tabular}

Os resultados mostram que apesar de administrarem pequenas empresas, os gerentes buscam lançar novos produtos, explorar novos mercados, ou acompanhar os mercados existentes. Em relação à característica analítica, estas empresas não têm a pretensão de serem as primeiras, mas sim atender o mercado com eficiência.

$\mathrm{Na}$ proposição deste artigo, entende-se que aqui poderia ter sido interessante a utilização de conceitos de redes, principalmente os estudos que fundamentam as relações na rede e as possibilidades de inovações em produtos e mercados, que é a característica da estratégia analítica. 
Revalorização do modelo de Miles: lições das teorias de redes para decisões estratégicas

B. Walter et al. (2010) analisaram seis escritórios de contabilidade de Curitiba para verificar suas estratégias. Para isso foram levantadas questões sobre o perfil das empresas e o conteúdo das estratégias adotadas. A amostra era constituída de empresas antigas, com mais de 28 anos no mercado.

Quatro dos seis escritórios analisados apresentam o conteúdo de estratégia analítica, pois estão preocupados com a qualidade dos serviços para satisfação dos clientes e em auferir lucro. Um deles apresenta um perfil mais prospector, enquanto que o sexto apresenta um perfil mais defensivo.

Segundo a proposta aqui defendida, o contexto das relações poderia explicar a posição divergente de dois escritórios, quando comparados com os outros quatro.

C. Pesquisa realizada por Rossetto (2000) teve como objetivo descrever o comportamento estratégico de três empresas da Indústria da Construção Civil. Para Rossetto (2000) este trabalho pretende aplicar e ampliar a teoria de Miles et al. (1978) investigando três pequenas empresas familiares no seu processo de adaptação estratégica, descrevendo como elas se comportaram ao longo de sua existência. $\mathrm{O}$ estudo privilegiou situações de eventos críticos para identificar o processo de mudança estratégica nas empresas. Segundo o autor, o uso do Modelo de Miles indicou que as três empresas seguiram a estratégia Analítica e que a mesma é predominante nas pequenas empresas desse negócio (ROSSETTO, 2000).

Este estudo é interessante por utilizar a técnica do incidente crítico. Talvez alguns dos incidentes tivessem origem nas relações da empresa com o mercado. A teoria de redes, então, seria competente para explicar a adoção de estratégias a partir das crises de relações e suas soluções no tempo.

D. Teixeira, Rossetto e Carvalho (2009) investigaram 22 hotéis em Florianópolis, Santa Catarina, incluindo o modelo de Miles entre as questões. Considerando as três dimensões do modelo, isto é, a capacidade empreendedora; a capacidade de engenharia e a capacidade administrativa, a estratégia prospectora obteve $38 \%$ de respostas e a analítica $31 \%$. Dominavam, portanto, as ações de inovações e busca de novos mercados.

Conforme proposta deste artigo, entende-se que o contexto ficou em segundo plano na pesquisa, já que valorizou os processos internos da empresa.

E. Estudo de uma amostra de lojas em shoppings de Maringá (PÉROLA e GIMENEZ, 2000) buscou identificar a estratégia adotada pelo dirigente da empresa de acordo com o modelo de 
Ernesto Michelangelo Giglio \& Luciana Massaro Onusic

Miles et al. (1978). Como variáveis importantes, os autores colocaram o tempo das empresas e o gênero de dirigentes. Os resultados sobre a escolha de estratégia podem ser vistos na Tabela 2.

Tabela 2 - As escolhas estratégicas de gerentes de lojas num shopping em Maringá - PR, utilizando o modelo de Miles

\begin{tabular}{lccccc}
\hline Estratégia & Analítica & Prospectora & Reativa & Defensiva & Soma \\
\hline Frequência & 39 & 22 & 13 & 10 & 84 \\
Porcentagem & 46,4 & 26,2 & 15,5 & 11,9 & 100 \\
\hline \multicolumn{7}{c}{ Fonte: Adaptado do texto de Pérola e Gimenez, 2000. }
\end{tabular}

Os autores concluíram que o modelo de Miles pode ser utilizado por qualquer tipo e porte de empresa. Para os propósitos deste artigo, observa-se que os pesquisadores estão buscando variáveis antecedentes que sejam capazes de explicar as escolhas, mas não consideram as conexões em rede, valorizando tempo de existência e gênero, entre outras. No caso do tempo existe uma percepção de que é uma variável importante, mas, conforme se interpreta na proposta deste artigo, o tempo decorrido está diretamente relacionado com a construção e manutenção de uma rede de relações. Essa perspectiva torna mais consistente a explicação da migração de estratégias das empresas, conforme o tempo vai passando.

F. Estudo realizado por Almeida, Antonialli e Ferraz (2011) teve como objetivo utilizar o modelo de Miles et al. (1978) para entender o comportamento estratégico de mulheres empresárias. A coleta se deu através de um questionário dividido em duas partes, sendo a primeira composta de questões com características demográficas da empresa e do gestor e a segunda parte com questões para identificar o comportamento estratégico adotado pela empresa conforme o modelo de Miles. A análise de setenta e cinco respostas revelou que 41,3\% das empresas adotam a estratégia analítica; 30,7\% seguem a estratégia prospectora; $14,7 \%$ a defensora e $13,3 \%$ a reativa.

Conforme a proposta deste manuscrito entende-se que a variável gênero, isolada, parece não ter poder de explicação, mas adicionada a análises de redes sociais poderia ganhar força. Será que mulheres apresentam uma forma mais característica de relações sociais nas redes, que poderia explicar a escolha da estratégia analítica, no seu dualismo entre inovar e manter mercados seguros?

G. Pesquisa realizada em Londrina- PR (GIMENEZ et al., 1999) com uma amostra de 107 empresas de uma população de 406 empresas com até 100 funcionários, de ramos variados da 
Revalorização do modelo de Miles: lições das teorias de redes para decisões estratégicas

indústria, comércio e serviços, buscou determinar a escolha estratégia conforme o modelo de Miles.

No estudo foram criadas variáveis dammy para as questões da pesquisa para que se conseguisse classificar as quatro diferentes estratégias em clusters. Foram apresentadas questões com variáveis demográficas, como por exemplo, idade da empresa, idade dos dirigentes, número de funcionários, entre outras. $\mathrm{O}$ instrumento mostrou-se capaz de discriminar as estratégias e criar os clusters, o que levou o autor a concluir que o modelo tem capacidade de discriminar as estratégias com um grau aceitável de confiabilidade. Os resultados sobre as escolhas estratégias são apresentados na Tabela 3.

Tabela 3 - As estratégias de uma amostra de pequenas empresas de Londrina, utilizando o modelo de Miles.

\begin{tabular}{lccccc}
\hline Estratégia & Analítica & Prospectiva & Reativa & Defensiva & Total \\
\hline Frequência & 48 & 24 & 19 & 16 & 107 \\
\hline \multicolumn{5}{c}{ Fonte: Adaptados de Gimenez et al. (1999). }
\end{tabular}

Novamente observa-se um esforço para se encontrarem variáveis importantes na determinação das escolhas estratégicas. Segundo a linha de interpretação deste trabalho, as variáveis de redes, tais como comprometimento, cooperação, centralidade, valores compartilhados, características do negócio são mais capazes de explicar as escolhas de estratégias do que variáveis demográficas.

H. O estudo realizado por Vasconcelos, Guedes e Candido (2007) propôs identificar as estratégias competitivas adotadas por empresários do setor de calçados de Campina Grande (Paraíba) e verificar a possível associação com seus estilos cognitivos. Para tal, foi realizada uma pesquisa descritiva e exploratória, com o uso de entrevistas com roteiro semi aberto, com uma amostra de 26 empresários do setor, num universo de 48 empresas.

O roteiro incluía questões sobre o modelo de Miles et al.(1978) e sobre o modelo de Kirton (1976), que trata de estilos na solução de problemas e tomada de decisão. Na análise entre os dois modelos o autor estabeleceu as seguintes relações: A. Sobre as estratégias competitivas: Nos setores e atividades econômicas mais homogêneas existe uma tendência da adoção do mesmo tipo de estratégia. Nos setores e atividades econômicas nas quais existe maior intensidade e velocidade de mudanças, existe uma tendência da adoção de estratégias prospectoras e analíticas, em detrimento das estratégias mais defensivas e reativas. B. Sobre associação entre estilo cognitivo e estratégia: Os que apresentam estilo Inovador adotarão, com maior frequência, estratégias prospectoras. Os que apresentam estilo Adaptador adotarão, 
Ernesto Michelangelo Giglio \& Luciana Massaro Onusic

em maior frequência, estratégias defensivas (VASCONCELOS, GUEDES e CANDIDO, 2007, p.130).

Os resultados mostraram a concentração em adotar a estratégia defensiva e a dominância do estilo cognitivo adaptativo. Segundo proposta aqui defendida, esta pesquisa poderia ter explorado as relações nas redes para melhor explicar a adoção dos tipos de estratégia para tomada de decisão. Por exemplo, a relação entre as características homogêneas do negócio e a adoção de estratégias semelhantes poderia ser explicada pelo conteúdo dos fluxos que correm entre os atores. Sendo homogêneo, o conteúdo dos fluxos entre os atores tende a ser redundante e imitativo, o que explicaria a repetição da escolha da estratégia.

I. Sob a coordenação dos autores, alunos de um curso de Graduação em Administração entrevistaram 56 gerentes de pequenas empresas dos ramos farmacêuticos, floricultura e serviços variados. Para a coleta de dados foi utilizado um instrumento adaptado por Gimenez (1999), a partir de original de Conant, Mokwa e Varadarajan (1990). Como o objetivo era também investigar crises passadas pelas empresas, havia a questão de como os empresários lidaram com a situação de crise. O resultado final das escolhas pode ser visto na Tabela 4.

Tabela 4 - Classificação da Estratégia dominante numa amostra de 56 pequenas empresas da Grande São Paulo

\begin{tabular}{ccccc}
\hline Estratégia & Serviços & $\begin{array}{c}\text { Distribuidor } \\
\text { de flores }\end{array}$ & Farmácias & Total \\
\hline Prospectora & 4 & 8 & 6 & 18 \\
Analítica & 3 & 5 & 10 & 18 \\
Reativa & 2 & 1 & 8 & 11 \\
Defensiva & 2 & 6 & 1 & 9 \\
Total & 11 & 20 & 25 & 56 \\
\hline \multicolumn{5}{c}{ Fonte: Elaborado pelo autor }
\end{tabular}

Esta amostra de pesquisas de aplicação do modelo cobriu 413 pequenas empresas, das regiões sul, sudeste e nordeste. O resultado da soma das pesquisas citadas é mostrado na Tabela 5. Mesmo considerando a falta de alguns dados, é possível concluir que a estratégia analítica é a dominante, o que significa que a empresa procura um balanço entre mercados estáveis e dinâmicos, oferecendo um leque de produtos e copiando as melhores práticas. Conforme Miles et al. (1978) nesta estratégia o pequeno empresário analisa o mercado e replica produtos de sucesso, ao mesmo tempo em que continua com seus produtos tradicionais. Em segundo lugar aparece a estratégia prospectiva, o que indica a escolha dos empresários em inovar produtos, processos e mercados. 
Revalorização do modelo de Miles: lições das teorias de redes para decisões estratégicas

Tabela 5 - A soma dos resultados de uma amostra de pesquisas brasileiras que aplicaram o modelo de Miles. Os campos com as letras n.f. (não fornecido) indicam que os pesquisadores não forneceram os dados

\begin{tabular}{lcccccccccc}
\hline & Caso A & Caso B & Caso C & Caso D & Caso E & Caso F & Caso G & Caso H & Caso I & Soma \\
\hline Analítica & 14 & 4 & 3 & 7 & 39 & 31 & 48 & n.f. & 18 & 164 \\
Prospectiva & 14 & 1 & 0 & 8 & 22 & 23 & 24 & n.f. & 18 & 110 \\
Reativa & 2 & 0 & 0 & n.f. & 13 & 10 & 19 & n.f. & 11 & 55 \\
Defensiva & 4 & 1 & 0 & n.f. & 10 & 11 & 16 & n.f. & 9 & 51 \\
Soma & 34 & 6 & 3 & 22 & 84 & 75 & 107 & 26 & 56 & 413 \\
\hline \multicolumn{8}{c}{ Fonte: elaborado pelos autores }
\end{tabular}

Os trabalhos revelam uma busca das variáveis antecedentes tais como tempo de existência da empresa, gênero do dono, geração de empregos, número de funcionários; as quais não caracterizam relacionamentos e contexto. $\mathrm{O}$ argumento da proposta deste artigo é que o modelo de Miles apontou, desde o início, a imbricação com o meio ambiente, mas as pesquisas não incluem essa categoria. Conforme já sugerido na introdução, um motivo pode ser a falta de conhecimentos suficientes sobre a imersão das empresas nas relações ambientais. Somente com os argumentos de Granovetter (1985) é que a Sociologia Economica pode ser reconhecida como importante, no seu argumento básico do imbricamento indissociável entre as relações sociais e as ações econômicas. Conforme será detalhado adiante, as afirmativas de Granovetter (1985) constituem uma das bases da proposta deste trabalho.

Um segundo motivo, de ordem metodológica, é a inexistência de instrumentos capazes de investigar essa imersão. Nos vários exemplos brasileiros apresentados que utilizaram o modelo de Miles, os pesquisadores buscaram atrelar os resultados a variáveis isoladas do contexto, como o gênero do dono, ou o número de empregos gerados. No entanto, nessas pesquisas existem sinais de que o contexto joga um papel importante, por exemplo, conforme a empresa cria uma rede de relações no tempo, que lhe possibilita mudar sua estratégia. Essa explicação é sustentada pelos argumentos de Nohria e Ecles (1992), quando afirmam que a competitividade e o comportamento de uma empresa tornam-se inteligíveis quando se explicita seu lugar na rede, sendo secundária a questão dos seus recursos isolados.

Um terceiro motivo, este derivado de inferência fundada em reflexões prévias, é a dificuldade dos pesquisadores em adotarem o paradigma da sociedade em rede, já que predomina há algumas décadas o modelo de competição isolada e, portanto, as pesquisas buscam comparar empresas entre si. Segundo Kuhn (1975) um paradigma deve ser abandonado quando os fatos se modificaram e esta parece ser a situação atual. 
Ernesto Michelangelo Giglio \& Luciana Massaro Onusic

Assim, entende-se que os pesquisadores estão deixando de lado a pista dada pelos próprios fundadores do modelo, quando, já na década de 1970, indicaram que as ações coletivas e o contexto organizacional eram tão importantes quanto os processos decisórios dos empresários. Defende-se que a inclusão de variáveis de redes traria mais qualidade aos instrumentos de coleta e análise.

A conclusão deste item é que existem esforços teóricos e operacionais para fundamentar, valorizar e utilizar o modelo de Miles, mas, segundo se defende, é nos conceitos de redes que se vislumbra uma alternativa teórica e metodológica mais capaz, quando consideramos os novos fatos das ações coletivas. No próximo item esses fundamentos serão apresentados.

\section{PROPOSTA DE INSERÇÃO DO MODELO DE MILES NA TEORIA DE REDES.}

Os argumentos da teoria de redes que importam para a sustentação da proposta de inserção do modelo de Miles nessa perspectiva são apresentados neste item. Trata-se de uma seleção das afirmativas sobre redes de negócios, já que um quadro completo do tema fugiria do objetivo deste manuscrito.

\subsection{Os fundamentos dos conceitos de redes e suas relações com as decisões estratégicas}

O formato em redes de negócios tem gerado um volume crescente de trabalhos científicos. Autores como Dwyer, Schurr e Oh (1987), Castells (1999), Pereira (2002), Verschoore e Balestrin (2006) têm ressaltado a importância de se criar um claro conceito de rede como explicação para os arranjos entre organizações, em substituição aos conceitos que se aplicam à empresa individual. As teorias de redes se iniciaram com alguns estudos econômicos, como as aglomerações italianas e o sistema Toyota; mas logo se difundiram na década de 1980, com o movimento de fusões e aquisições. Aos poucos, a área foi incorporando os conceitos das redes sociais, que é um tema clássico da Sociologia, criando a generalização de que todas as organizações operam em redes (NOHRIA e ECLES, 1992).

Autores nacionais (VERSHOORE e BALESTRIN, 2006; LOPES e BALDI, 2009; GIGLIO, 2010) defendem a idéia de que não é suficiente usar modelos racionais e econômicos para se entender as redes e as decisões das empresas nela imersas. As empresas estão comprometidas nas redes (GRANOVETTER, 1985) e essa imersão é que explica suas ações. Conforme Granovetter as decisões de produção estão inextricavelmente ligadas ao fluxo social entre as organizações. $\mathrm{Na}$ esteira dos fundamentos das teorias sobre redes encontra-se o trabalho de Castells (1999). Conforme o autor, a sociedade atual está organizada 
Revalorização do modelo de Miles: lições das teorias de redes para decisões estratégicas

na forma de redes, diferente da organização social anterior, de pequenos grupos, como a família. Uma empresa é e está numa rede, mesmo que seus integrantes não a reconheçam. $\mathrm{O}$ sistema de produção, isto é, a teia de ligações de produção entre as empresas, seria um subsistema do sistema geral de estrutura da sociedade em rede.

Tanto as abordagens de redes sociais, como encontrada em Granovetter (1985), quanto a abordagem da sociedade em rede, encontrada em Castells (1999) convergem na aceitação de que o fenômeno de rede apresenta complexidade, imprevisibilidade, fluidez, dinâmica entre equilíbrios e desequilíbrios, ordem e desordem. Essas características, investigadas nas teorias da complexidade e na teoria dos sistemas, indicam que a sociedade atual se caracteriza por uma teia de conexões, que evoluem e se reorganizam dinamicamente. As relações empresariais constituem uma das facetas dessa sociedade em rede e as escolhas estratégicas são respostas resultantes dessa malha.

Conforme Castells (1999) os comportamentos das pessoas, incluindo as decisões de negócios e de estratégias, seriam manifestações da sociedade em rede. No campo especifico de negócios, a rede não apresenta hierarquia claramente definida (portanto o poder é fluido), sendo diferente das estruturas organizacionais clássicas e não segue leis estritas de mercado (de procura e de oferta), sendo diferente das estruturas organizacionais dirigidas aos consumidores, ou aos concorrentes. É outro formato organizacional. Os próprios autores do modelo aqui discutido (MILES et al., 1978) afirmaram que a rede dinâmica era o novo formato organizacional para explicar a estrutura e as ações nas empresas.

Nessa linha de uma sociedade em rede, Nohria e Ecles (1992) afirmam que todas as empresas estão em redes, quer reconheçam, ou não sua existência e suas ligações. Assim, numa pesquisa, é possível construir o mapa de um grupo de empresas a partir de qualquer ponto, isto é, de qualquer nó da rede e estabelecer inferências entre as ações da empresa e sua posição na rede. Uma metáfora que auxilia é entender a rede como uma espiral infinita. Cada ator se une a outros atores, em ligações que se desdobram tanto na vertical (na linha do negócio propriamente dito), como na horizontal (na linha de terceiros que exercem influencia sobre as decisões dos atores no negócio, tais como bancos, governo, sindicatos).

Outra defesa da noção de rede aplicada aos negócios vem do conceito de embeddedness de Granovetter (1985). A afirmativa é que existe uma inseparável união entre fatores comerciais e sociais que criam um comprometimento de cada ator na rede. Alguns pesquisadores brasileiros utilizam a expressão imersão social para se referir a esse fenômeno. A idéia de imersão é bastante antiga na Sociologia de Pequenos Grupos, explicando que um grupo proporciona ao sujeito a segurança e identidade que ele busca, mas, ao mesmo tempo, 
Ernesto Michelangelo Giglio \& Luciana Massaro Onusic

impõe limites e diretrizes de ação. Este dualismo da segurança e da falta de liberdade foi recolocado por DiMaggio (1992) para o caso de ligações entre empresas, a partir da expressão o paradoxo de Nadel. É licito propor-se que uma das diretrizes resultantes da imersão é a ação estratégica.

As redes de empresas representam uma forma inovadora de obter competitividade e sobreviver no mundo globalizado, ou seja, elas indicam caminhos estratégicos. Nessa linha, Pinto e Loiola (2007) afirmam que as redes de empresas possibilitam um aumento na eficiência operacional e no desenvolvimento de novas competências; facilitam a inserção das empresas no mercado e a obtenção de vantagens competitivas sustentáveis, devido ao maior fluxo de informações e conhecimentos compartilhados.

Ocorre que obter inovações, ampliar a atuação no mercado, controlar recursos são algumas das características das estratégias do modelo de Miles et al. (1978), portanto existe aí uma interface que pode ser desenvolvida. Autores como Balestrin e Vargas (2004) e Kanter (2000) ensaiaram afirmativas nessa direção.

Com estas bases, sobre a teoria da sociedade em rede e sobre as redes como provedoras de vantagens estratégicas entende-se ser possível entrar na discussão da interface entre esse embasamento e o modelo de Miles.

\subsection{Inserção teórica e metodológica do modelo de Miles na teoria de redes}

O modelo de estratégias de Miles se funda nas afirmativas dos processos de escolha de Child (1972). Conforme visto, as pesquisas sobre o modelo buscaram definir as variáveis que determinam essas escolhas, ora valorizando características pessoais, como idade e tempo de experiência no negócio, ora valorizando os recursos internos da empresa, como tecnologia. Os próprios criadores do modelo, no entanto, afirmavam ser necessário inserir a proposta numa nova realidade, referindo-se às redes de negócios (MILES et al.; 1986, p.68).

Afirma-se, neste trabalho que é possível colocar a teoria de redes como base para a investigação do contexto das relações de uma empresa num mercado. Nessa perspectiva, a origem e o conteúdo da escolha estratégica estão no contexto do negócio e na rede de relações que o estrategista está imerso. Uma das vantagens dessa posição, comparada com outras teorias, é que os fluxos, os conteúdos das redes são acessíveis, ao passo que modelos que utilizam, por exemplo, estilos cognitivos, usam conceitos que apresentam dificuldades operacionais.

A interface entre o modelo de Miles e a teoria de redes foi apontada pelos próprios autores, já na primeira apresentação dos argumentos, na década de 1970, só que não existiam 
Revalorização do modelo de Miles: lições das teorias de redes para decisões estratégicas

conceitos suficientes de redes para sustentar e desenvolver essa interface. Nas décadas de 1980 e 1990 a discussão sobre redes de negócios evoluiu e adquiriu importância, criando-se uma cultura cientifica sobre os conceitos, metodologias e gerencia de redes. Daí a justificativa de revisitar o modelo, dando-lhe a sustentação que faltou naquela época.

Qual o núcleo dessa sustentação? Conforme visto na fundamentação teórica, alguns autores da área de redes (NOHRIA e ECLES, 1992; GRANOVETTER, 1985; CASTELLS, 1999; POWER, SMITH-DOWERR, 1994; GULATI, 1998; HAKANSSON, 2006) afirmam que essa perspectiva teórica permite compreender com maior capacidade do que outras teorias temas relevantes tais como poder, aprendizagem, dependência de recursos e posição estratégica. Nesta linha de argumentação, os recursos internos não têm importância de forma isolada, mas apenas quando são lançados e utilizados na rede. Os recursos competitivos de fato advêm dos fluxos entre os atores, os quais possibilitam otimizar processos e ações comerciais, inclusive aprendendo a utilizar os recursos isolados das empresas participantes. Em outras palavras, na teoria de redes o grande recurso é ter acesso e saber usar os recursos coletivos. A partir desses usos podem surgir vantagens e caminhos estratégicos. Sobre este ponto, Nohria e Ecles (1992) afirmam que a decisão sobre uma estratégia e a posição estratégica de uma empresa pode ser adequadamente compreendida na teia de relações dessa empresa.

Para dar mais sustentação à proposição do trabalho, foram apresentados alguns textos da literatura internacional que afirmam que a teoria de redes é um fundamento competente para embasar o modelo de Miles, especialmente quando aplicado em pequenas empresas. Nessa esteira, o relato das escolhas de estratégias de 413 pequenas empresas brasileiras mostrou que o modelo é perfeitamente aplicável. Essas pesquisas, no entanto, não apresentaram análises do contexto e da teia de relações das empresas. Entende-se que algumas perguntas diretas sobre o lugar da empresa na rede e o conteúdo de seus fluxos teriam oferecido outras linhas conclusivas para esses estudos. Por exemplo, ao invés de perguntar "Quanto tempo está no negócio", perguntar "Com quais empresas você tem uma relação mais constante de troca de informações"; "Em quais empresas você confia e por que?"; "Você segue a estratégia das empresas com as quais mantém mais contato, ou nesse grupo cada um segue um caminho independente?”. São perguntas de relacionamento, comprometimento e interdependência, que são algumas variáveis valorizadas na abordagem de redes.

Ter estratégias inovadoras, por exemplo, conforme Prahalad e Ramaswamy (2004) e também em Sternberg (2000) dependem do contexto de ligações externas das empresas da REAd I Porto Alegre - Edição 74 - № 1 - jan/abr 2013 - p. 192-218 
rede e da existência de fluxos com baixas restrições. As redes da Internet onde fabricantes e consumidores trocam idéias seria um exemplo desse formato. Já a estratégia defensiva só é possível numa rede relativamente fechada e estável, o que restringe as inovações. A estratégia analítica, por seu turno, emerge a partir de uma rede aberta, com laços fracos, porém com certo grau de centralização, com regras definidas sobre os comportamentos dos empresários. As redes de revendas e serviços automotivos seriam um exemplo.

Esses são argumentos que sustentam a proposta de que a escolha estratégica está vinculada ao contexto da rede na qual a empresa está imersa.

Metodologicamente a proposta implica em se colocar questões das variáveis mais valorizadas de redes de negócios no instrumento de coleta. São questões sempre dirigidas ao relacionamento entre os atores, seja nos seus conteúdos comerciais (os fluxos técnicos), seja nos seus conteúdos sociais (os fluxos sociais). Variáveis tais como confiança, comprometimento, conflitos de interesses, dependência, jogos de poder, sistemas de trocas de informações, rotinas de encontros, indicam situações de relacionamento. Essas respostas, unidas com informações sobre o contexto do negócio podem, no entendimento deste trabalho, oferecer mais dados para explicar as escolhas estratégicas, do que as variáveis que apareceram nas pesquisas brasileiras.

\section{COMENTÁRIOS FINAIS}

O objetivo deste trabalho foi revalorizar a tipologia de estratégias de Miles colocandoa num quadro teórico de redes, focando a importância da posição das pequenas empresas em uma teia de relações, utilizando para isto, os conceitos de redes, principalmente as afirmativas de Castells (1999), Granovetter (1985), Nohria e Ecles (1992). Como o modelo foi apresentado na década de 1970, quando as discussões sobre redes eram ainda incipientes, o trabalho busca contribuir na medida em que recoloca o modelo e suas aplicações no contexto contemporâneo de redes, especialmente quando se trata de pequenas empresas. A proposição orientadora é que a opção por uma das quatro estratégias do modelo por parte dos empresários pode ser explicada a partir de suas conexões na rede em que estão imersos. Para alcançar o objetivo do trabalho investigou-se a tendência das análises e das aplicações do modelo numa amostra de artigos nacionais e internacionais.

$\mathrm{Na}$ literatura internacional verificou-se que os próprios autores do modelo afirmaram que estava ocorrendo uma nova forma de organização, as redes dinâmicas (MILES et.al, 1986). Em trabalhos subsequentes (MILES e SNOW, 1992; MILES et al., 1997) os autores discutiram as falhas que podem ocorrer se os gerentes não souberem agir no formato de redes. 
Revalorização do modelo de Miles: lições das teorias de redes para decisões estratégicas

Apesar da união do tema de estratégias e das relações ambientais feita no artigo original de Miles, os dois assuntos não evoluíram em conjunto, seguindo trilhas distintas. Este trabalho busca recuperar essa interface, indicando que os conceitos de redes apresentam capacidade explicativa sobre o comportamento dos empresários nas escolhas das estratégias.

$\mathrm{Na}$ literatura nacional foram analisados artigos sobre 413 pequenas empresas, nas quais o modelo foi aplicado, no estudo das escolhas de estratégias e buscando-se valorizar diferentes variáveis. Em alguns casos de forma explícita, em outros de forma mais implícita, esses trabalhos utilizaram alguns raciocínios e pressupostos das teorias de redes, tais como cooperação. Em sua maioria, no entanto, buscaram relacionar as escolhas com variáveis estanques, tais como idade, gênero e estilo cognitivo. Os artigos apresentaram a conclusão que o modelo tem capacidade explicativa e consegue distinguir as opções de estratégias conforme a variável definida pelo pesquisador.

$\mathrm{Na}$ presente proposta, a interpretação é que nesses trabalhos faltaram questões sobre o contexto e a rede de ligações da empresa, as quais poderiam explicar as possibilidades de inovações em alguns casos; em outros a questão da divergência de escolhas de estratégia e em outros o comportamento de decisão dos empresários. Algumas variáveis valorizadas nos citados estudos, como o tempo de existência da empresa, não têm muito sentido quando aparecem isoladas. O tempo decorrido, por exemplo, possibilita o desenvolvimento de uma teia de ligações, que, na perspectiva de redes, é o contexto que influencia as possibilidades de movimentos estratégicos. Falta a conexão entre a escolha de estratégias e o pano de fundo de uma rede de relações, que pode explicar a migração de estratégias das empresas conforme o passar do tempo. Nos artigos investigados nota-se que existe um esforço em fazer relações de tempo de existência da empresa, gênero dos administradores, entre outros, mas não uma relação sobre redes das empresas. Uma das explicações possíveis para esta linha de pesquisa talvez seja a falta de instrumentos adequados, o que vem se desenvolvendo nas teorias de redes.

Sobre os princípios de redes utilizados no trabalho, Nohria e Ecles (1992) afirmam que o recurso competitivo mais importante de uma empresa é o seu lugar na rede de relações. Os autores também afirmam que todas as empresas estão em redes, quer reconheçam, ou não a sua existência. Assim, neste trabalho, entende-se que existem esforços teóricos e operacionais para fundamentar, valorizar e utilizar o modelo de Miles, mas é nos conceitos de redes que se vislumbra uma alternativa teórica e metodológica mais capaz, quando consideramos os novos fatos das ações coletivas. 
Com este enquadre teórico, as escolhas estratégicas adquirem novo sentido e vigor, considerando a situação atual de mercado, onde a competição se configura cada vez mais entre grupos.

Entende-se que o artigo contribui teoricamente ao apresentar argumentos que sustentam a proposição de que os conceitos de redes, mais claramente desenvolvidos nas décadas de 1980 e 1990, constituem um suporte defensável para o modelo de estratégias de Miles, apresentado na década de 1970. Naquela época os autores já vislumbraram o formato em rede, mas não contavam com uma teoria mais estabelecida. Atualmente, os paradigmas econômicos e sociais sobre redes (GRANOVETTER, 1985; NOHRIA e ECLES, 1992; CASTELLS, 1999) mostram-se capazes de explicar as ações dos empresários.

Seguindo algumas idéias de pesquisadores (WEGNER, MISOCSKY, 2010) uma tarefa atual importante é desenvolver metodologias mais adequadas ao fenômeno de redes. De fato, analisando os trabalhos nacionais já relatados, observa-se a tendência de se utilizar questionários e valorizar variáveis que podem estar atuando isoladamente. Os dois pontos podem ser discutidos e criticados. Os questionários podem ser formas interessantes de coleta, mas os dados se referem muito mais a rede percebida, do que a rede de fato. Uma pergunta tal como "Quantas pessoas participam da rede?" pode obter uma resposta percebida sobre quantos são atuantes (numa interpretação da palavra "participam”), ao invés do universo de ligações fortes e fracas da rede. O segundo ponto, sobre variáveis, também é discutível. $\mathrm{O}$ fenômeno das redes é caracteristicamente coletivo e de relacionamento, portanto as variáveis a serem utilizadas numa pesquisa devem captar e reproduzir essas características. $O$ gênero do empresário, a quantidade de funcionários e o tempo de empresa podem ser substituídos por facilidades de relacionamentos, contatos entre funcionários de empresas distintas e teia de relações fortes construídas no tempo, por exemplo.

Em outras palavras, um dos grandes ensinamentos metodológicos das teorias de redes é que o objeto de investigação deve reproduzir o fluxo entre atores e não os recursos, ou características isoladas. Com a relativização da dominância das teorias da competição isolada, a perspectiva de redes oferece outra visão, quando utiliza o argumento de que o comportamento empresarial é influenciado pela rede de relações. Esta interconexão cria possibilidades de se entender não só o comportamento de um empresário, mas de toda uma cadeia de empresas, interligada, com fluxos compartilhados. São esses fluxos que influenciam o comportamento. 
Revalorização do modelo de Miles: lições das teorias de redes para decisões estratégicas

O artigo é parte de uma etapa de trabalho dos autores, atualmente buscando construir um modelo teórico e instrumentos de pesquisa a partir dos conceitos de redes, onde o modelo de Miles possa ser aplicado.

\section{REFERÊNCIAS}

ALMEIDA, I.; ANTONIALLI, L.; GOMES, A. Comportamento Estratégico das Mulheres Empresárias: Estudo Baseado na Tipologia de Miles e Snow. Revista Ibero-Americana de Estratégia, São Paulo, v. 10, p. 102-127, 2011.

ANSOFF, H.I. Strategic Management. New York: Wiley, 1979.

BALESTRIN, A.; VARGAS, L. A Dimensão Estratégica das Redes Horizontais de PMEs: Teorizações e Evidências. Revista de Administração Contemporânea-RAC, Edição Especial, Curitiba, v.8, p.203-227, 2004.

BARBOSA, J.; TEIXEIRA, R. Gestão estratégica nas empresas de pequeno e médio porte. Revista de Gestão, São Paulo, v.10, n.3, p. 31-42, 2003.

BAUM, J. Ecologia Organizacional. In CLEGG, S.; HARDY, C.; NORD, W. Handbook de Estudos Organizacionais. São Paulo: Atlas, v.1., cap. 5, p.137-195, 1998.

BURREL, G.; MORGAN, G. Sociological paradigms and organizational analysis: Elements of sociology of corporate life. London: Heinemann, 1979.

CASTELLS, M. A sociedade em rede. São Paulo: Paz e terra, v.1, 1999.

CHANDLER, A. D., Jr. (1977). The visible hand: the managerial revolution in American business. Cambridge, MA: Harvard University Press.

CHILD, J. Organizational structure, environment and performance: The role of strategic choice. Sociology, Sidney, v.6, n.1, p.1-22, jan.; 1972.

CONANT, J.; MOKWA, M.; VARADARAJAN, P. Strategic types, distinctive marketing competencies and organizational performance: a multiple-measures-based study. Strategic Management Journal, Chicago, v.11, n.5, p.365-383, 1990. 
DEMO, P. Metodologia Científica. 3a.ed. São Paulo: Atlas, 1995.

DESARBO, W. et al. Revisiting the Miles and Snow strategic framework: Uncovering interrelationships between strategic types, capabilities, environmental uncertainty and firm performance. Strategic Management Journal, Chicago, v.26, p.47-74, 2004.

DIMAGGIO, P. Networks and organizations. Boston: Harvard, 1992.

DVIR, D.; SEGEV, E.; SHENHAR, A. Technology's varying impact on the success of strategic business units within the Miles and Snow typology. Strategic Management Journal, Chicago, v.14, n.2, p.155-161, 1993.

DWYER, F.; SCHURR, P.; OH, S. Developing Buyer-Seller Relationships. Journal of Marketing, Chicago, v.51, n.2, p.11-27, 1987.

GIGLIO, E. Análise e crítica da metodologia presente nos artigos brasileiros sobre redes de negócios e uma proposta de desenvolvimento. VI Encontro de Estudos OrganizacionaisENEO, Florianópolis, 2010.

GIMENEZ, F.; PELISSON, C.; KRUGUER, E.; HAYASHI, P. Estratégia em pequenas empresas: uma aplicação do modelo de Miles e Snow. Revista de Administração Contemporânea- RAC, Curitiba, v.3, n.2, p.53-74, mai/ago, 1999.

GRANOVETTER, M. Economic Action and Social Structure: The Problem of Embeddedness. The American Journal of Sociology, Chicago, v.91, n.3, nov., p.481-510, 1985.

GULATI, R. Alliances and networks. Strategic Management Journal, Chicago, v.19, n.4, p.293-317, 1998.

HAKANSSON, H. Business relationships and networks: consequences for economic policy. The Antitrust Bulletin, Amsterdam, v.51, n.1, p.143-163, spring, 2006.

HAMBRICK, D. Some tests of the effectiveness and functional attributes of Miles and Snow's strategic types. Academy of Management Journal, Birmingham, v.26, n.1, p.05-26, 1983.

HOFER, E. WELGACZ, H.T., LORENZI, A.G.A., DAMKE, E. Um estudo de formação de estratégias no contexto de pequenas empresas da cidade de Curitiba-PR. In GIMENEZ, F.; 
Revalorização do modelo de Miles: lições das teorias de redes para decisões estratégicas

FERREIRA, J.; RAMOS, S. Empreendedorismo e estratégia de empresas de pequeno porte 3Es2Ps. Curitiba: Champagnat, 2010, p.141-158.

HOFFMANN, R. et al. As estratégias da micro empresa varejista e seus estágios de informatização. Revista de Administração Mackenzie- RAM, São Paulo, v.10. n.2, p.110134, 2009.

HOFFMANN, V.; MOLINA-MORALES, F.; MARTINEZ-FERNANDES, M. Redes de Empresas: Proposta de uma tipologia para classificação aplicada na indústria de cerâmica de revestimento. Revista de Administração Contemporânea- RAC, Curitiba, 1a. Edição Especial, p.103-127, 2007.

KANTER, R. O futuro depende dos relacionamentos. HSM- Management, São Paulo, n.2, ano 4, p. 112-118; mai/jun, 2000.

KUHN, T. A Estrutura das Revoluções Científicas. São Paulo: Perspectiva, 1975.

LATOUR, B. Reassembling the social. Oxford: Oxford Press, 2005.

LOPES, F.; BALDI, M. Redes como perspectiva de análise e como estrutura de governança: uma análise das diferentes contribuições. Revista de Administração Pública, Rio de Janeiro, v.43, n.5, p.1007-1035, set./out., 2009.

MARSDEN, P. Network data and measurement. Annual Review of Sociology, Palo Alto, v.16, p.435-463, 1990.

MILES, R.; SNOW, C.; MEYER, A.; COLEMAN, H. Organizational strategy, structure and process. The Academy of Management Review, Georgia, v.3, p.546-562, jul, 1978.

MILES, R.; SNOW, C. Organizations: New concepts for new forms. California Management Review, Berkeley, v.27, n.3, Spring, p.62-72, 1986.

MILES, R.; SNOW, C. Causes of Failure in Network Organizations. California Management Review, v.34, n.4, p.53-72, summer, 1992.

MILES, R. et al. Organizing in the knowledge age: Anticipating the cellular form. The Academy of Management Executive, Birmingham, v.11, n.4, p. 7-20, nov, 1997. 
MOORI, R.; GHOBRIL, A.; MARCONDES, R. Alinhamento das prioridades competitivas entre compradores e vendedores de máquinas e equipamentos. Revista de Administração do Mackenzie- RAM, São Paulo, v.10, n.4, p.156-182, jul/ago, 2009.

MORGAN, G. Imagens da organização. São Paulo: Atlas, 1996.

NOHRIA, N.; ECCLES, R.(ed.). Networks and organizations: structure, form, and action. Boston: Harvard Business School Press, 1992.

PEREIRA, R. A Influência das Organizações em Redes no Papel e nas Atividades de Marketing. Anais do XVI Encontro da Anpad- ENANPAD, Salvador, 2002, CD.

PÉROLA, A.; GIMENEZ, F. Estratégia em pequenas empresas: uma aplicação dos modelos de Miles e Snow e Kirton nas lojas varejistas dos shopping-centers de Maringá - Pr. Anais do XXIV Encontro da Anpad - ENANPAD, Florianópolis, Setembro, 2000, CD.

PINTO, F.; LOIOLA, E. Comportamento das firmas em redes de produção. Revista Eletrônica de Gestão Organizacional, Recife, v.5, n.1, p.21-37, jan-mai., 2007.

PORTER, M. Competitive strategy. New York: Free Press, 1980.

POWELL, W.; SMITH-DOERR, L. Networks and economic life; in SMELSER, N.; SWEDBERG, R. (edts) The Handbook of Economic Sociology. Princeton: Princeton University, 1994.

PRAHALAD, C.; RAMASWAMY, V. O futuro da competição: como desenvolver diferenciais inovadores em parceria com os clientes. Rio de Janeiro: Elsevier, 2004.

ROSSETO, C. R. O comportamento estratégico segundo a teoria de Miles e Snow: um estudo multicaso em três empresas familiares na indústria da construção civil - setor de edificações. In: ENCONTRO NACIONAL DE ENGENHARIA DE PRODUÇÃO: desenvolver competências para a produção internacional, perspectivas para países emergentes, 2000, São Paulo. Anais, São Paulo: USP/ABEPRO, 2000. CD-ROM.

SEBRAE, Coleção de Estudos e Pesquisas, outubro, 2011. Disponível no endereço http://www.biblioteca.sebrae.com.br/bds/BDS.nsf/45465B1C66A6772D832579300051816C/ \$File/NT00046582.pdf, acesso em 29/10/2011.

SEVERINO, A. Metodologia do trabalho cientifico. 21a. Ed, São Paulo: Cortez, 2007. 
Revalorização do modelo de Miles: lições das teorias de redes para decisões estratégicas

SHORTELL, S.; ZAJAC, E. Perceptual and archival measures of Miles and Snow's strategic types: a comprehensive assessment of reliability and validity. Academy of Management Journal, Birmingham, v.33, n.4, p.817-832, 1990.

SLATER, S.; NARVER, J. Product-market strategy and performance: an analysis of the Miles \& Snow strategy types. European Journal of Marketing, London, v.27, n.10, p.33-51, 1993.

STERNBERG, R. Innovation Networks and Regional Development. European Planning Studies, London, v.8, n.4, p.389-407, 2000.

TEIXEIRA, O.; ROSSETO, C.; CARVALHO, C. A relação entre o ambiente organizacional e o comportamento estratégico no setor hoteleiro de Florianópolis- SC. Revista Turismo, Visão e Ação, v.11, n.2, p.157-174, mai/ago, 2009.

VASCONCELOS, Ana Cecilia Feitosa de., GUEDES, I. A., CANDIDO, G. A. Aplicação dos modelos de Miles e Snow e Kirton em pequenas e médias empresas: um estudo exploratório. GEPROS - Gestão da Produção, Operações e Sistemas, Bauru, v.3, n.2, p.123- 132, mai/jun, 2007.

VERSCHOORE, J.; BALESTRIN, A. Fatores competitivos das empresas em redes de cooperação. Anais do XXX Encontro da Anpad, ENANPAD, Salvador, Setembro, 2006, CD.

VIZEU, F. Pesquisas sobre redes interorganizacionais: uma proposta de distinção paradigmática. Anais do XXVII Encontro da Anpad, ENANPAD, São Paulo, Setembro, 2003, CD.

YIN, R. Estudo de caso: planejamento e métodos. 3.ed. Porto Alegre: Bookman, 2005.

WALTER, S. A., ROCHA, D.T., HOKAI, S.R., VIDAL, E.A.A., GIMENEZ, F.A.P. O processo de desenvolvimento de estratégias: Um estudo de caso comparativo em pequenas empresas de contabilidade. In GIMENEZ, F.; FERREIRA, J.; RAMOS, S. Empreendedorismo e estratégia de empresas de pequeno porte 3Es2Ps. Curitiba: Champagnat, 2010, p.159-176.

WEGNER, D.; MISOCSKY, M. C. Avaliação de desempenho de redes de pequenas empresas: contribuições da abordagem da produção de sentido. Revista Organizações e Sociedade, Salvador, v.17, n.53, p.345-361, Abril/Junho, 2010. 